\title{
A Descriptive Study of the Current Situation of COVID-19 in Algeria
}

\author{
Mohamed Lounis ${ }^{1 \star}$
}

\begin{abstract}
${ }^{1}$ Department of Agro-veterinary Science, Faculty of Natural and Life Sciences, University of Ziane Achour, BP 3117, Road of Moudjbara, Djelfa 17000, ALGERIA
\end{abstract} *Corresponding Author: lounisvet@gmail.com

Citation: Lounis M. A Descriptive Study of the Current Situation of COVID-19 in Algeria. Electron J Gen Med. 2020;17(6):em253. https://doi.org/10.29333/ejgm/8287

\begin{tabular}{|c|c|}
\hline ARTICLE INFO & ABSTRACT \\
\hline Received: 1 Apr. 2020 & etected in Wuhan (China) in December 2019 is quickly spreading \\
\hline Accepted: 6 May 2020 & $\begin{array}{l}\text { across the globe leading to a shocking number of 3,305,595 cases and 235,861 deaths on May 1st, 2020. Algeria is } \\
\text { the fourth most affected country in Africa with a number of } 4154 \text { positive cases and } 453 \text { deaths. The objective of } \\
\text { the current manuscript is to describe the actual situation of COVID-19 in Algeria. }\end{array}$ \\
\hline
\end{tabular}

Keywords: COVID-19, coronavirus, Algeria, pandemic

\section{INTRODUCTION}

Since its first report in Wuhan (China) on December 2019, the novel Coronavirus disease 2019 (COVID-19) has quickly spread through the world generating a pandemic of global interest (1). As qualified by Musinguzi and Asamoah, 2020, "COVID-19 is spiralling like wild fire" and the case number has exceeded all expectations (2). The number of positive cases is $3,685,129$ in 187 countries and regions with a number of deaths that reached 258,051 determining an actual estimated casefatality rate of $7 \%(3)$.

Algeria, like other countries through the world has not escaped this pandemic respiratory disease. The actual situation shows a number of 4997 positive cases and 476 deaths (4).

The present work is conducted to describe the current situation of COVID-19 in Algeria, the measures implemented for the prevention and the treatment of this disease and finally the contribution of the Algerian scientific community.

\section{ORIGIN AND FIRST CASES}

Before the apparition of COVID-19 in the country, Algeria was considered as one of the three African countries with the highest importation risk of COVID-19 from China with Egypt and South Africa (5). Furthermore, it was part of the 13 top priority countries identified by the World Health Organization on the basis of their direct links and volume of travel to China (6). However, as in the border country of Morocco (7), the first cases came all from Europe (Especially from France, Italy and Spain) (8).

Except the case of an Italian citizen reported COVID-19 positive on February 25 in the department of Ouargla (actually with 115 cases), the true starting point of the epidemic is reported on March $1^{\text {st }}$ of two national citizens who came from
France in the department of Blida which became the epicenter of the epidemic (8).

Since May $1^{\text {st }}$, all the 48 departments of Algeria were affected with a number varying from 2 to 865 of positive cases (4).

Geographically, the highest number of cases is reported in the north of Algeria, especially in the department of Blida ( 865 cases) and its border departments like Algiers (563 cases), Ain Defla (237 cases), Tipaza (188 cases) and Medea (121). With 286 positive cases, the Department of Oran in the North western is considered as the third most affected department. On the other hand, another outbreak of the disease is observed in the last days in some departments of the north eastern like Setif (243 cases), Constantine (221 cases), Bordj Bou Arreridj (167 cases) and Bejaia (151 cases). The number of positive cases in the department of Ouargla (115 cases) in the South (where the first case was reported) starts also to become alarming (4).

Regarding their origin, except for a few cases of secondary contaminations especially from the department of Blida, almost all cases in all departments are considered as primary contamination with an European origin (4).

\section{MORBIDITY}

Since the first case reported on February 25, Algeria has recorded a number of 4997 COVID-19 positive cases on Mai 6 (Figure 1). It is the fourth most affected country in Africa after Egypt (7588), South Africa (7572) and Morocco (5382) and the $55^{\text {th }}$ most affected in the world (3).

Regarding age and gender of the positive patients, data shows that the most affected categories are those aged between 25 and $49(38.5 \%)$ and older person of more than 60 years (34.8\%) (Figure 2) and men (56.5\%) seem to be more affected than women (43.5\%) (4). 
Daily confirmed COVID-19 cases

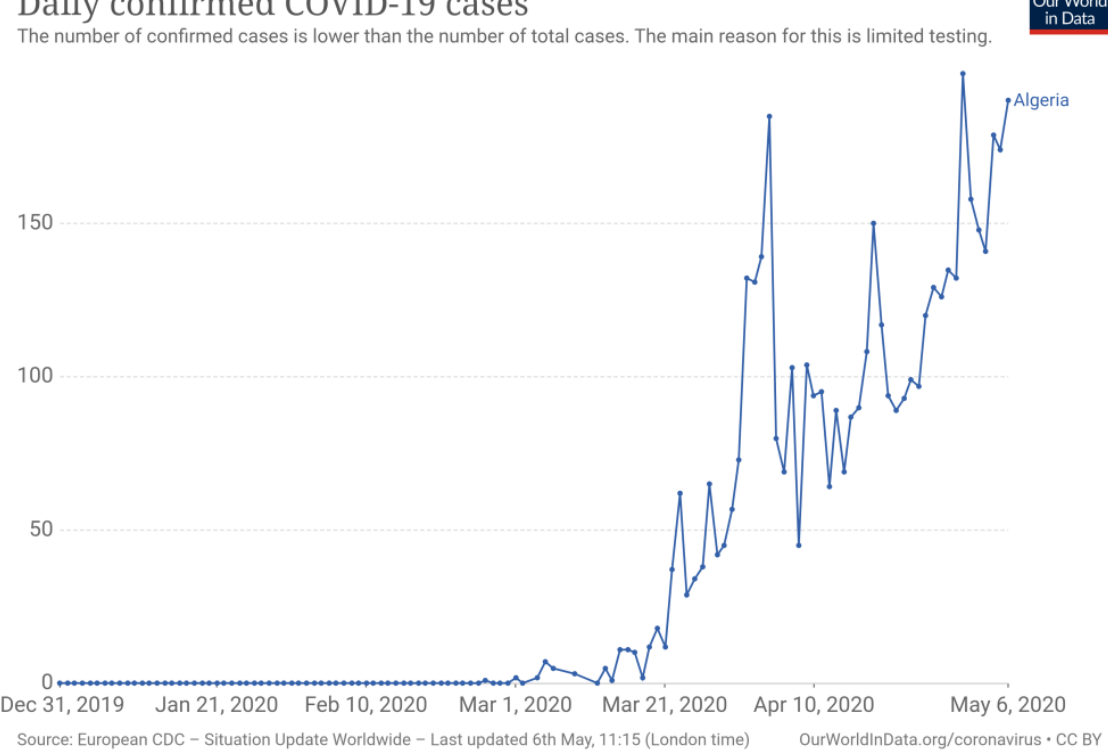

Figure 1. Daily confirmed COVID-19 cases in Algeria

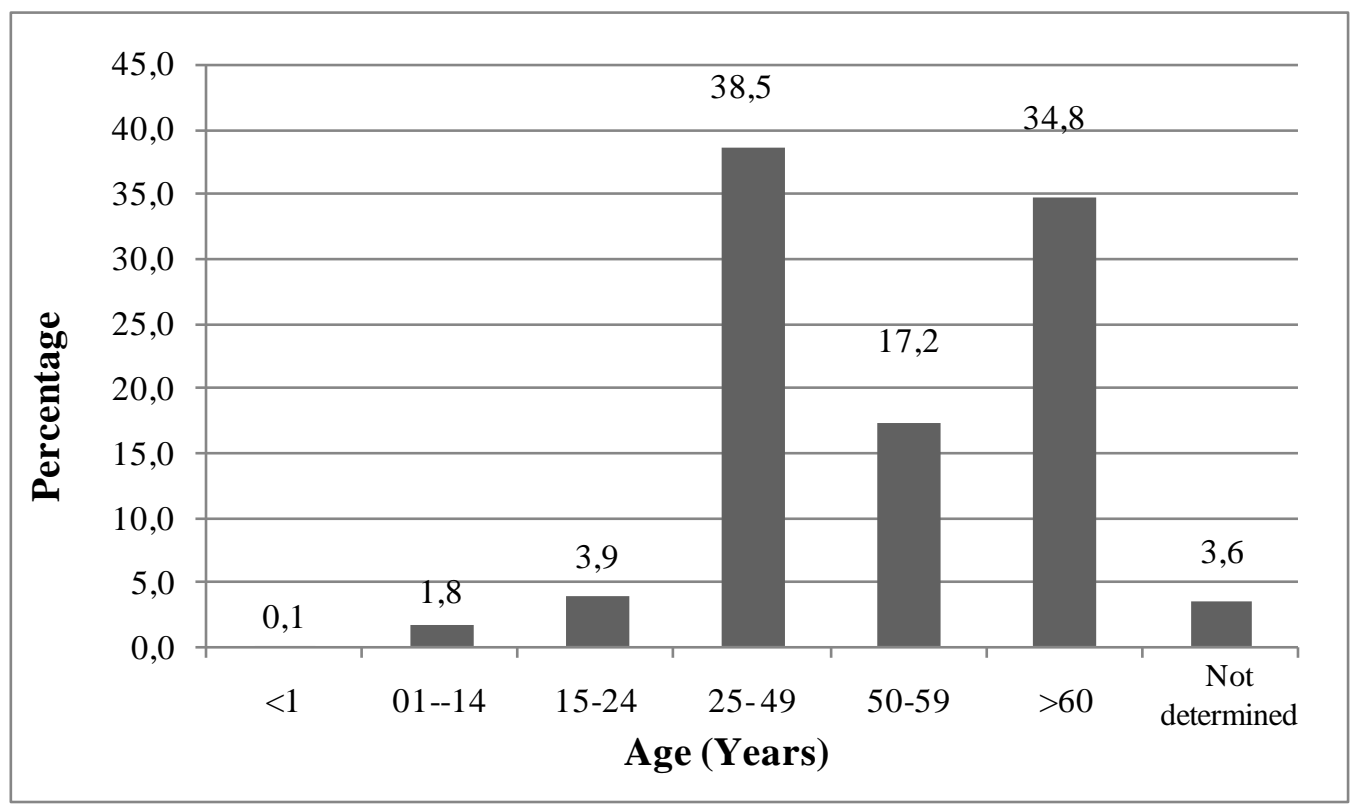

Figure 2. Distribution of COVID-19 positive patients according to their age

It should be noted that this number represents a morbidity of about 110 cases/million of the population witch is higher than the mortality recorded in Egypt (70 cases/ millions) but lower than those reported in Morocco (146 cases/million) and south Africa (128 cases/million) (10).

At last, these numbers are to take with some care since they don't reflect the real situation due to the limited number of realized tests (see below). Furthermore, a number of 4091 positive cases (on April 30) were diagnosed using radiology and scanner increasing the total number to about 8298 positive cases (4).

\section{MORTALITY AND LETHALITY RATES}

The number of total death related to COVID-19 in Algeria is 476 (4). This number is the highest in Africa and the $30^{\text {th }}$ highest in the world (6). When related to the total population, this number represents about 11 deaths/million. This rate remain higher than those reported in the other African countries like South Africa (2 deaths/millions), Egypt (4 deaths/million) and Morocco (5 deaths/ millions) (9). Of notes, $65 \%$ of the total died persons were more that 65 years old (4).

Regarding fatality, the estimated rate is about $9.5 \%$. This rate is one of the highest in the world after the most affected countries like Spain (11.7\%), Italy (13.8\%), France (15\%) and UK (15\%) (3). However, this rate is to take with care for different reasons: This rate seems to decrease in time with the increasing of the number of realized tests (Figure 3). Also the number of presumed positive cases is estimated at 8298 (taking in account those diagnosed with radiology and those treated with chloroquine) which decreases the lethality rate to $5.7 \%$. 


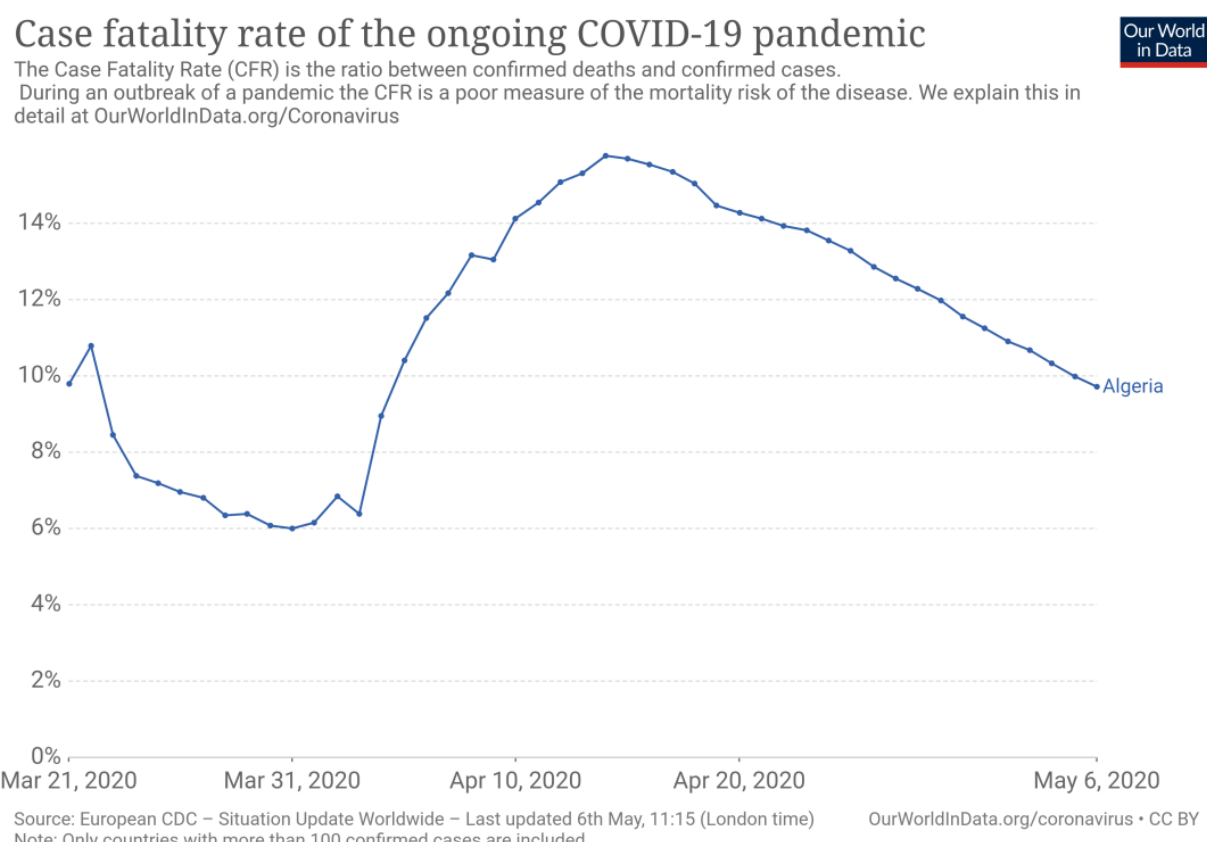

Figure 3. Case fatality rate of the ongoing COVID-19 in Algeria

\section{RECOVERY}

Among the total number of positive cases, 2197 patients have recovered from this disease. This number is higher than those reported in Morocco (1969) and Egypt (1730) but lower than the reported number of 2746 recovered patients in South Africa (9).

Of note since March 23, Algeria as other countries in the world has adopted the Chloroquine (Hydroxychloroquine)/ Azithromycin protocol for the treatment of patients with COVID-19. First recommended for "some cases" the treatment was generalized from April 6 for all COVID-19 positive cases (10).

The treatment consists of the administration of Chloroquine (500mg) twice a day for 5 to 7 days or hydroxychloroquine $(200 \mathrm{mg})$ three times/ day for 10 days; in association with azithromycin (500mg) twice a day for 5 days. Alternatively, Lopinavir/Ritonavier (200/50mg) could be administrated twice/day for 5 to 7 days for patients with chloroquine contraindications (10).

Currently, 8298 patients were treated with this protocol (4).

\section{LABORATORY TESTING}

The laboratory analysis is one of the weakest links of Algeria in dealing with COVID-19 pandemic. In the first days, the number of realized tests was estimated at 50 tests per day in the Pasteur Institute of Algiers, the only laboratory approved to realize them. This number has reached more than 400 tests per day with the opening of 20 new laboratories in different departments which increased the average number of realized tests to about 200 tests per day since the apparition of the COVID-19 in Algeria (11).This number has a direct link with the high daily new cases detected in the last days.
The total number still however unknown and is estimated at about 10000 tests. This number is extremely lower than the number of the realized tests in Morocco $(52,100)$, Egypt $(90,000)$ and South Africa $(268,656)(9)$.

\section{PREVENTION}

Shortly after the detection of the first cases, the Algerian government has started to implement a set of preventive measures to enhance social distancing and to limit the spread of the virus.

These measures consist on the travel cancellation and isolation of repatriated citizens, the restriction of all public gathering by the closure of schools, universities and all educational institutions, mosques and cult places and suspension of collective prayers, the suspension of all private and public common transport, rail traffic and at last a total lockdown in the department of Blida and a partial containment of all the other departments (8).

These measures first temporarily adopted until April 5 have been delayed to 19 , then 29 and later until May $14^{\text {th }} 2020$.

Results of these measures were considered satisfactory by the Algerian government. However, the number of positive cases in the last days beside the increasing capacities of realized tests is worrying. This 'high' number is associated with the decision of the government to alleviate these measures for economical and social reasons since these days coincide with the beginning of the holy month of Ramadan. Consequently, an apparent relax was observed which could led to a second peak of the pandemic curve in the next few days.

\section{COVID-19 AND SCIENTIFIC PUBLICATIONS}

Despite the global interest of the COVID-19 pandemic and despite the huge number of scientific publications through the 
world, a little published works about COVID-19 in Algeria are available in the international databases.

The only available data are two statistical modeling studies analyzing the spread of the disease (12) and the evaluation of the confinement effects in the number of COVID-19 (13); and two descriptive publications about the disease (14) and the prevention strategy adopted in Algeria (8).

Other preprints papers were also submitted including three papers about modeling the spread of COVID-19 cases $(15,16)$ and the evaluation of the preventive measures in Algeria (17) and two In silico works concerning the effect of artemisnin as a substitute to chloroquine (18) and the potential inhibition activity of black cumin against the Novel coronavirus (19). At last, the virus was fully sequenced by the Pasteur Institute of Algiers but only the preliminary results are available at the institute site (20). All this shows a very low number of published data which may pushes the Algerian scientific community to be involved in the struggle against this pandemic.

\section{CONCLUSION}

This work describes the current situation of COVID-19 in Algeria. We showed that even the situation seemed to be under control, the increasing number and the remarked relax in the last days is worrying and a possible peak of the curve of the disease in the next few days is not to exclude. The current situation has not escaped the attention of the Algerian president who warned about the eventual return to more restrictive measures. Subsequently, some Walis (governors) have ordered again the hardening of these measures in their department territories.

As recommendations, we suggest that the hardening of social distancing measures and the mandatory mask wearing are more than needed. The government must also use all its resources for the total respect of these measures and also to ensure vital needs for the low income and needy families.

\section{REFERENCES}

1. Gupta PK, Bhaskar P, Maheshwari S. Coronavirus 2019 (COVID-19) Outbreak in India: A Perspective so far. J Clin Exp Invest. 2020;11(4):em00744. https://doi.org/10.5799/ jcei/8220

2. Musinguzi G, Asamoah BO. The Science of Social Distancing and Total Lock Down: Does it Work? Whom does it Benefit? Electron J Gen Med. 2020;17(6):em230. https://doi.org/ $10.29333 /$ ejgm/7895

3. Johns Hopkins University of Medecine. Coronavirus resource center. 2020. Available at: https://coronavirus. jhu.edu/map.html (Accessed: May 6, 2020).

4. Algerian health and hospital reform minister: Carte épidémiologique. Available on: https://www.covid19.gov. dz/carte/ (Accessed: May 6, 2020).

5. Gilbert M, Pullano G, Pinotti G, Valdano E, Poletto C, Boëlle PY, et al. Preparedness and vulnerability of African countries against importations of COVID-19: a modelling study. Lancet 2020:395. https://doi.org/10.1016/S01406736(20)30411-6
6. World Health Organisation: WHO ramps up preparedness for novel Coronavirus in the African region. 2020. available at: $\quad$ https://www.afro.who.int/news/who-ramps-uppreparedness-for-novel-coronavirus-in-the-african-region (Accessed: May 1, 2020).

7. El Baz S, Boudjemâa I. Coronavirus disease 2019 (COVID19): Morocco interrupting the transmission by ethics, logistic and therapeutic efforts. J Clin Experim Invest. 2020;11(4):em00743. https://doi.org/10.5799/jcei/8214

8. Lounis M. COVID-19 in Algeria: Chronology and evaluation of preventive actions. European Journal of Medical and educational Technologies 2020;13(1):em2001. https://doi.org/1030935/ejmets/8012

9. Coronavirus updates; 2020. Available at: https://www.worldmeter.info/coronavirus/ (Accessed: May 6, 2020).

10. Elwatan. Lutte contre le coronavirus : Le traitement à la chloroquine se généralise. Available at: https://www.elwatan.com/edition/actualite/lutte-contrele-coronavirus-le-traitement-a-la-chloroquine-segeneralise-26-03-2020 (Accessed: May 1, 2020).

11. APS (Algerian Press Service): http://www.aps.dz/santescience-technologie/104593-covid-19-hausse-sensible-dunombre-de-tests-quotidiens-dans-les-laboratoires-de-lipa (Accessed: May 1, 2020).

12. Boucenna N, Bouharati K, Bouharati I, Hamdi-Cherif M, Aggravating and progression factors of COVID-19: Intelligent analysis Averroes Europ. Med J, 2020;2(2):1-8.

13. Moussaoui A, Auger $P$, Prediction of confinement effects on the number of covid-19 outbreak in Algeria, 2020. hal02547128v2. Available at: https://hal.archivesouvertes.fr/hal-02547128v2

14. Boukhatem MN, Novel Coronavirus Disease 2019 (COVID19) Outbreak in Algeria: A New Challenge for Prevention. J Community Med Health Care, 2020;5(1):1035.

15. Hamidouche M. COVID-19 outbreak in Algeria: A mathematical Model to predict cumulative cases. [Submitted]. Bull World Health Organ. https://doi.org/10.2471/BLT.20.256065

16. Boudrioua MS and Boudrioua A. Predicting the COVID-19 epidemic in Algeria using the SIR model. 2020, medRxiv preprint. https://doi.org/10.1101/2020.04.25.20079467

17. Hamidouche M, COVID-19 Epidemic in Algeria: Assessment of the implemented preventive strategy, 2020; medRxiv preprint. https://doi.org/10.1101/2020.04.21.20074443

18. Sehailia M, Chemat S. In-silico Studies of Antimalarialagent Artemisinin and Derivatives Portray More Potent Binding to Lys353 and Lys31-Binding Hotspots of SARSCoV-2 Spike Protein than Hydroxychloroquine: Potential Repurposing of Artenimol for COVID-19. ChemRxiv ${ }^{\mathrm{TM}}$. PrePrint. https://doi.org/10.26434/chemrxiv.12098652.1

19. Bouchentouf S, Missoum N, Identification of Compounds from Nigella Sativa as New Potential Inhibitors of 2019 Novel Coronasvirus (Covid-19): Molecular Docking Study. ChemRxiv. Preprint. https://doi.org/10.26434/chemrxiv. 12055716.v1

20. Institut Pasteur d'Algérie: Premières analyses de séquences des souches algeriennes de SARS-COV-2. 2020. Available at: https://pasteur.dz/fr/dz/285-premieresanalyses-de-séquenes-des-souches-algeriennes-de-sarscov-2 (Accessed: May 1, 2020). 